\title{
PERFORMANCE EVALUATION AND SELECTION OF BEST MODE OF TRANSPORTATION IN LAGOS STATE METROPOLIS
}

\author{
Solomon Olasunkanmi Odeyale ${ }^{1}$, Oguntola Jelili Alamu², Elizabeth Olubunmi \\ Odeyale $^{3}$ \\ ${ }^{1}$ Mechanical Engineering Department, Olabisi Onabanjo University, Ibogun Campus, Nigeria \\ ${ }^{2}$ Mechanical Engineering Department, Osun State University Oshogbo, Osun State Nigeria \\ ${ }^{3}$ Department of Mathematics/Statistics, Lagos State University School of Communication, Nigeria
}

Received 9 May 2013; accepted 19 July 2013

\begin{abstract}
This paper describes an application of the Saaty's Analytic Hierarchy Process (AHP) and fuzzy set for selecting the best mode of transportation in Lagos State metropolis. Seven transportation alternatives were considered: private car, okada, keke-napep, train, ferry, commercial bus and taxi. These alternative modes of transportation were evaluated with nine decision criteria: low transportation cost, low environmental effect, large capacity, improved safety, high comfort, high accessibility, improved reliability, low number of interchanges required and faster journey time. This method is used in such a way that information from commuters, who were asked to express their opinions in the ranking of decision criteria, was used in hierarchy prioritization of the criteria and expressed in fuzzy numbers with triangular membership functions. The method is applied at two levels: beginning with the finding of fuzzy weights for the decision criteria, followed by finding the fuzzy weights for the alternatives under each of the decision criteria. Fuzzy scores for the alternatives were obtained.
\end{abstract}

Keywords: prioritization, mode, transportation, multi-criteria decision analysis, fuzzy set, analytic hierarchy process, triangular.

\section{Introduction}

The transportation system of a location can increase the productivity and quality of life at the same time if they are selected properly. Selection of a good mode of transportation is essential for the sustainability of commuters' life and the environment. In evaluating a mode of transportation, its impact on life, environment and all other entities surrounding us should not be left out. A good mode of transportation should ensure effective movement of commuters and should not affect the resources around us negatively.

${ }^{1}$ Corresponding author: solomon.odeyale@gmail.com
The transportation system in Lagos State presently is getting more complex. There are over seven means of transportation in the metropolis, compared to other states in Nigeria. Therefore, evaluating the performance of transportation modes and selection process may be a complex process because of the different criteria which approach the subject from different aspects. Under certain conditions, evaluation of these transportation modes may seem more explicit. However, the criteria that contain uncertainties or cannot be given precisely are usually expressed in linguistic terms by decision makers, thus making fuzzy-AHP 
a more natural approach to these kinds of problems.

This paper is organized as follows: Section 2 gives a brief description of the case study; Section 3 shows the literature review; Section 4 proposes a method for evaluating and selecting the best mode of transportation; Sections 5 and 6 present the concluding remarks and recommendation, respectively.

\subsection{Objective of Research}

"Until you can measure something and express it in numbers, you cannot manage it (Odeyale et al., 2013). Hence the objective of this paper is:

- To perform a quantitative performance evaluation of the modes of transportation in Lagos State.

- To analyze the various modes of transportation and select the best.

\section{Case Study}

Lagos State is an administrative division of Nigeria, located in the southwestern part of the country. The smallest in area of Nigeria's states, Lagos State is arguably the most economically important state of the country, making it the nation's largest urban area. Its actual total population is disputed between the official Nigerian Census of 2006, and a much higher figure claimed by the Lagos State Government which was 21 million.

The state is located on the south-western part of Nigeria on the narrow coastal flood plain of Bight of Benin. It lies approximately on longitude $3.3833^{\circ} \mathrm{E}$ and latitude $6.4500^{\circ} \mathrm{N}$. Lagos State is bounded in the North and East by Ogun State of Nigeria, in the West by the Republic of Benin, and in the South by the Atlantic Ocean. It has five administrative divisions of Ikeja, Badagry, Ikorodu, Lagos Island and Epe. Territorially, Lagos State encompasses an area of 358,862 hectares or 3,577 sq. $\mathrm{km}$.

\subsection{Mode of Transportation in Lagos State}

There are various alternative means of transportation in Lagos State, but for the course of this research, only seven alternative means of transportation were considered for evaluation. These modes of transportation are listed below:

1. Private car - This is a personal car belonging to a commuter and can carry it anywhere at his or her time of convenience.

2. Okada - Okada is the popular name given to motorcycle in Lagos, it is a twowheeled road vehicle powered by an engine.

3. Keke Napep - This is the popular name given to tricycle in Lagos, it is a pedal-driven vehicle with two wheels at the back and one at the front. It was first introduced in Lagos as a means of transportation by the former military administrator of Lagos Colonel Burba Marwa and it was called keke marwa then.

4. Train - This is a series of railroad cars moved as a unit by a locomotive or by integral motors. The railway network and stations within the Lagos metropolis are shown in Fig. 1 below.

5. Ferry - This is a small sized ship for conveying passengers and goods, especially over a relatively short distance and as a regular service. Fig. 2 shows the stations and routes of ferry services within the metropolis.

6. Commercial bus - This is popularly 
known as danfo or molue in Lagos. It is a bus used to carry passengers at rates specified in tariffs, charges may be computed per passenger (as in regular

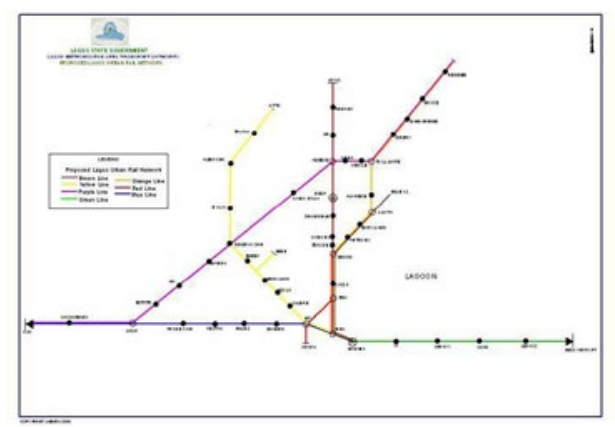

Fig. 1.

Railway Network in Lagos Metropolis

Source: www.lamata.com.ng

The decision criteria used for the evaluation are listed below and briefly explained:

1. Cost of transportation: The money spent on boarding a mode of transportation.

2. Environmental effect: This is the impact of the mode of transport on the environment, such as noise, air pollution, emission of greenhouse gases, etc.

3. Faster journey time.

4. Safety: How safe the mode of transport is.

5. Comfort of the passenger.

6. Accessibility: The convenience in accessing the mode of transport.

7. Reliability: How reliable the mode of transport is.

8. Capacity: The number of passengers the mode of transport can carry at a time.

9. Number of mode interchange required: This means; whether the mode of transport can carry you to your exact route service).

7. Taxi - This is a means of transportation like a car used to convey passengers in return for a payment or a fare.

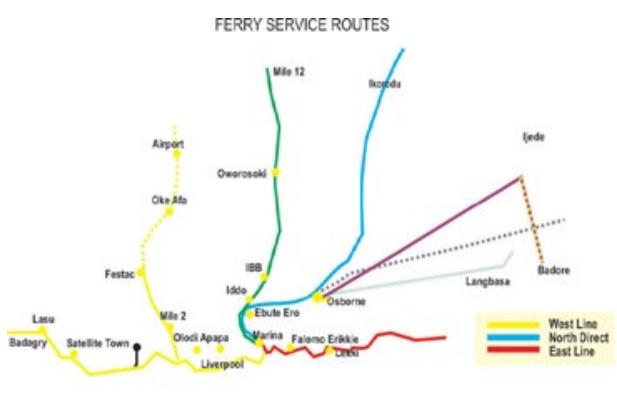

Fig. 2.

Ferry Service Routes in Lagos Metropolis

destination or you will need to board another mode of transport to get to your destination. E.g. okada/taxi can carry you to your exact destination, but commercial buses might only drop you at the bus stop and you may require walking or taking another mode of transport to your destination.

\section{Literature Review}

Multiple Criteria Decision Making (MCDM) is an important branch of decision making that deals with the decision problems under the presence of a number of decision criteria. It involves Multi Objective Decision Making (MODM) and Multi Attribute Decision Making (MADM) (Climaco, 1997). In the MODM approach, there are no predetermined alternatives and criteria to be ranked; the MODM tries to optimize more than one objective function subject to a set of constraints. On the other hand, MADM 
includes sets of alternative solutions to be evaluated against a set of attributes or criteria which are difficult to quantify (Pohekar and Ramachandran, 2004). Analytical hierarchy process (AHP) is one of the most frequently applied MADM methods for various decision making problems.

AHP is a multi-criteria decision-making method developed by Saaty (Saaty and Vargas, 1982). It aims at quantifying relative weights for a given set of criteria on a ratio scale. AHP has two features that differentiates it from other decision-making approaches. The first is; it provides a comprehensive structure to combine the intuitive rational and irrational values during the decision making process while the other is its ability to judge the consistency in the decision-making process using the consistency index. Despite the various benefits and usefulness of AHP, several limitations have been reported in the literature and some modifications were suggested to deal with these limitations. The said method tries to capture the decision maker's knowledge but, it lacks the ability of fully reflecting the human thinking style. In other words, the AHP method is not capable of handling the inherent subjectivity and ambiguity associated with the mapping of one's perception to an exact number (Pan, 2008). Linguistic and vague descriptions could not be solved easily by the AHP unless by the development of fuzzy decision-making.

Based on this problem, Buckley (1985) developed a fuzzy-AHP model and after this study various developments of fuzzyAHP methods and applications have been carried out (Chang, 1996; Wang and Yang, 2007). Yager (1978) presented some ideas on the application of fuzzy sets to multiobjective decision making and emphasis on a means of including diverging degrees of importance to different objectives. Laarhoven and Pedrycz (1983) presented a fuzzy method for choosing among a number of alternatives under conflicting criteria. All these were fuzzy versions of Saaty's pair wise comparison method. The opinions of the decision-makers, i.e. ratios are expressed in the form of fuzzy numbers with triangular fuzzy sets/functions. First fuzzy weights for the decision criteria are computed followed by the fuzzy weights of alternatives under each of the decision criteria. Finally, using suitable combination of these results, fuzzy scores of the alternatives are obtained based on which optimal choice is made. Zimmerman also established this fuzzy set based approach that can be found in his book (Zimmermann, 1987). Mechefske and Wang (2001) proposed fuzzy linguistic approach to select optimum maintenance and conditionbased strategy.

Some recently published studies on fuzzyAHP are given as follows: Huang et al. (2008) used fuzzy-AHP for selection of government sponsored research and development project in Taiwan. Wang and Chin (2008) proposed a method for fuzzy-AHP which utilizes a linear goal programming model to derive normalized fuzzy weights for fuzzy pairwise comparison matrices. Arslan and Khisty (2005) proposed a hybrid model that uses concepts from fuzzy logic and AHP, this model was proposed for transportation route choice. Tuzkaya and Onut (2008) applied fuzzy analytic network process to select transportation mode between Turkey and Germany. Tuzkaya (2009) used fuzzyAHP in evaluating the environmental effect of transportation mode. However, the application of fuzzy-AHP methodology for the evaluation and selection of best mode of transportation in a metropolis has not been seen in literature. 


\section{Methodology}

\subsection{Data Source and Collection}

Questionnaires were shared to commuters under the case study to evaluate the criteria on how important they were to them on the scale of $1-10$, where 10 was most important and 1 was least important. The evaluation was summed up and the percentage is shown below.

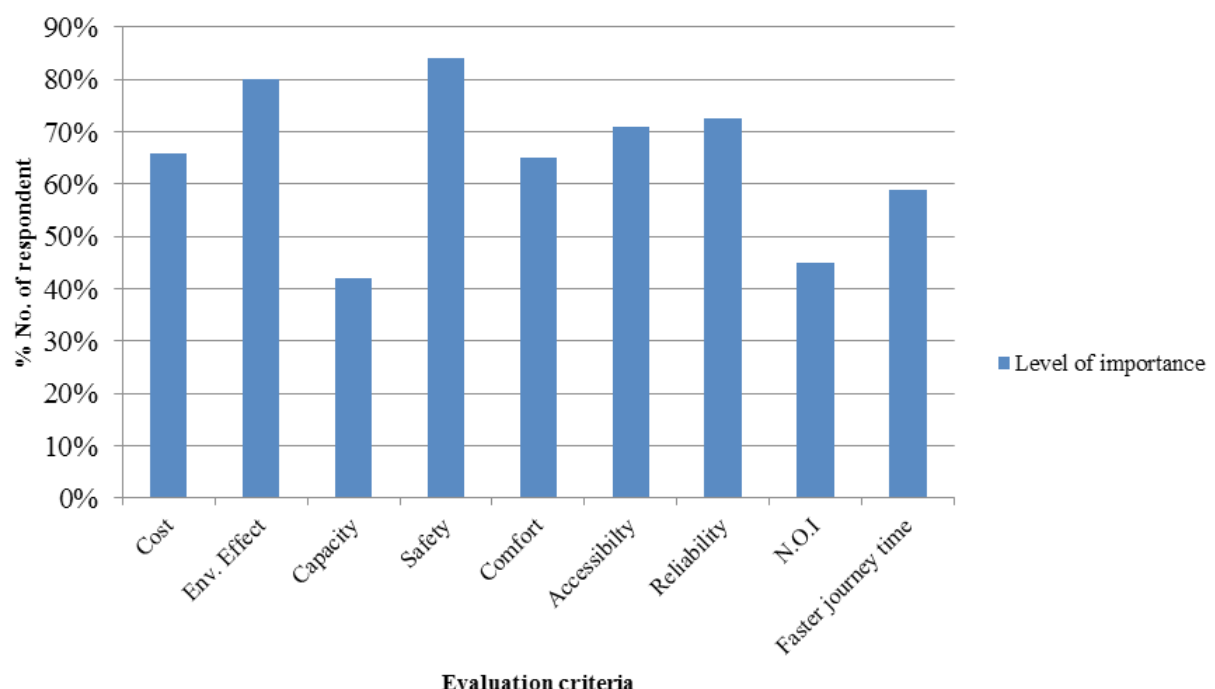

Fig. 3.

Relative Importance of Criteria to Commuters

Fig. 3 shows the commuters' response obtained from the survey carried out in order to be able to prioritize the criteria based on how important they were to commuters in Lagos State. Hence for this paper, the data obtained from the commuters were used for hierarchy prioritization and the criterion with the highest level of importance had the highest priority while the criterion with the lowest percentage had the lowest priority.

\subsection{Fuzzy Numbers}

Special class of fuzzy numbers suitable for this application is used in this paper. Triangular fuzzy numbers and some operations performed on them, such as addition, multiplication and inversion are defined in this section. Some of the definitions, being special cases of definitions of fuzzy numbers by Dubois and Prade (1980) are given as follows:

\subsubsection{Triangular Fuzzy Numbers}

A fuzzy number, which indicates a fuzzy set, addresses the definition of fuzzy set theory (Kahraman et al., 2003). A triangular fuzzy number shown in Fig. 4 must have the following properties:

$\mu_{M}(x)=0$, for all $x \in(-\infty, L)$

$\mu_{M}(x)$ is increasing on $[L, M]$ 
$\mu_{M}(x)=1$ for $x=M$

$\mu_{M}(x)$ is strictly decreasing on $[M, U]$

$\mu_{M}(x)=0$, for all $x \in(U, \infty)$

A fuzzy number $M$ on $\check{R}(=(-\infty,+\infty))$ is said to be a triangular fuzzy number if its membership function $\mu M: R \rightarrow[0,1]$ is equal to (Eq. (1)):

$\mu_{M}(X)=\left\{\begin{array}{c}\frac{l}{m-l} x-\frac{l}{m-l}, x \in[l, m] \\ \frac{l}{m-u} x \frac{u}{m-u}, x \in[m, u] \\ 0, \quad \text { otherwise }\end{array}\right\}$

with $l \leq m \leq u, l$ and $u$ stand for the lower and the upper limit of the support $M$, respectively, and $m$ for the modal value. The triangular fuzzy number, as given by Eq. (1), will be denoted by $(l, m, u)$, as shown in Fig. 4 . The support of $M$ is the set of elements $\{\mathbf{x} \in \check{R}$ / $1<x<u\}$.

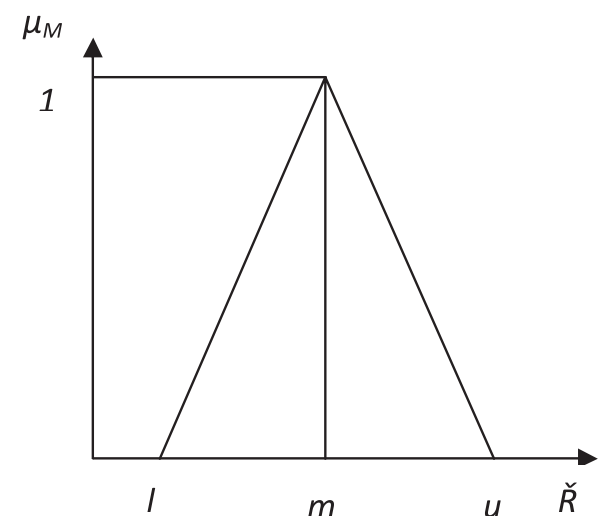

Fig. 4.

Membership Function of a Triangular Fuzzy Number

\subsubsection{Arithmetic Operations on Triangular Fuzzy Numbers}

Some important fuzzy arithmetic operations (Van Larhoven and Pedrcyz, 1983) used in this paper are given in this section.

a) Addition: Consider two TFNs $M_{1}=\left(l_{1}, m_{1}\right.$, $\left.u_{1}\right)$ and $M_{2}=\left(l_{2}, m_{2}, u_{2}\right)$. Then,

$M_{1} \oplus M_{2}=\left(l_{1}+l_{2}, m_{1}+m_{2}, u_{1}+u_{2}\right)$

b) Multiplication:

$M_{1} \oplus M_{2} \approx\left(l_{1} l_{2}, m_{1} m_{2}, u_{1} u_{2}\right)$

c) Inverse:

$(l, m, u)^{-1} \approx\left(\frac{1}{u}, \frac{1}{m}, \frac{1}{l}\right)$

d) Defuzzication (Centroid method):

$x_{\text {crisp }}=(l+m+u) / 3$

\subsection{Saaty's Priority Theory}

The Analytic Hierarchy Process (Saaty and Vargas, 1982) is a powerful and flexible decision making process to help people set priorities and make the best decision when both qualitative and quantitative aspects of a decision need to be considered. By reducing complex decisions to a series of one-on-one comparisons, then synthesizing the results, AHP not only helps decision makers arrive at the best decision, but also provides a clear rationale that it is the best. Designed to reflect the way people actually think, Dr. Thomas Saaty developed AHP in the 1970's. The 
AHP engage decision makers in structuring a decision into smaller parts, proceeding from the goal to objectives to sub-objectives down to the alternative courses of action. Decision makers then make simple pair wise comparison judgments throughout the hierarchy to arrive at overall priorities for the alternatives. The analytic hierarchy process allows users to assess the relative weight of multiple criteria (or multiple alternatives against a given criterion) in an intuitive manner. Its major innovation was the introduction of pair wise comparisons. Pair wise comparisons is a method that is informed by research showing that when quantitative ratings are unavailable and also, humans are good at recognizing whether one criteria is more important than another. Dr. Thomas Saaty, the inventor of the AHP methodology, established a consistent way of converting such pair wise comparisons ( $X$ is more important than $Y$ ) into a set of numbers (Yager, 1978; Saaty and Vargas, 1982; Verma, 2006) representing the relative priority of each of the criteria. For this, we devise a new fuzzy (in the form of TFN's) intensity scale of importance as given in Table 1. Fig. 5 represents the triangular fuzzy set scale for Table 1 as explained under section 4.2.1.

\section{Table 1}

Intensity of Importance on Fuzzy Set Scale

\begin{tabular}{|l|l|l|}
\hline $\begin{array}{l}\text { Intensity of Importance as } \\
\text { T.F.N's }\end{array}$ & Definition & Explanation \\
\hline$[1,1,1]$ & Equal importance (EI) & $\begin{array}{l}\text { Two activities contribute equally to the } \\
\text { objective. }\end{array}$ \\
\hline$[2,3,4]$ & $\begin{array}{l}\text { Weak importance of one over another } \\
\text { (WI) }\end{array}$ & $\begin{array}{l}\text { Experience and judgment slightly } \\
\text { favours one activity over another. }\end{array}$ \\
\hline$[4,5,6]$ & Essential or strong importance (SI) & $\begin{array}{l}\text { Experience and judgment strongly } \\
\text { favours one activity over another. }\end{array}$ \\
\hline$[6,7,8]$ & Demonstrated importance (DI) & $\begin{array}{l}\text { An activity is strongly favoured and its } \\
\text { dominance demonstrated in practice. }\end{array}$ \\
\hline$[8,9,10]$ & Absolute importance (AI) & $\begin{array}{l}\text { The evidence favouring one activity over } \\
\text { another is of the highest possible order } \\
\text { of affirmation. }\end{array}$ \\
\hline $\begin{array}{l}\text { Reciprocals of } \\
\text { above nonzero }\end{array}$ & $\begin{array}{l}\text { If activity } i \text { has one of the above nonzero } \\
\text { numbers assigned to it when compared } \\
\text { with activity } j \text {, then } j \text { has the reciprocal } \\
\text { value when compared with i. }\end{array}$ & \\
\hline
\end{tabular}

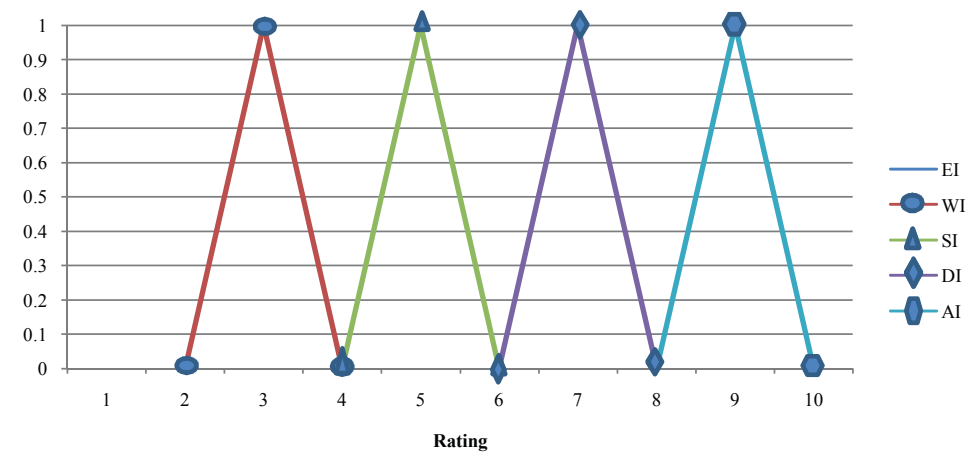

Fig. 5.

Graphical Representation of Fuzzy Set Scale 


\subsection{Performance Evaluation of Best Model of Transportation}

The basic aim is to choose between set of alternatives, given some decision criteria. Let $A=\left\{a_{i}\right\} ; i=1,2, \ldots n$ be the set of decision alternatives and $C=\left\{c_{j}\right\} ; j=1,2, \ldots m$ be the set of criteria according to which the desirability of an alternative is to be judged. The aim here is to obtain the optimal alternative with highest degree of desirability with respect to all relevant criteria. This problem is a multi-criteria decision making problem that is tackled by many researchers working in the area of decision-making in a non-fuzzy as well as fuzzy environment (Zimmermann, 1987; Zimmermann, 1985).

We considered seven alternatives: private car $\left(A_{1}\right)$, okada $\left(A_{2}\right)$, keke napep $\left(A_{3}\right)$, train $\left(A_{4}\right)$, ferry $\left(A_{5}\right)$, commercial bus $\left(A_{6}\right)$ and taxi $\left(A_{7}\right)$. The decision criteria are: low transportation cost $\left(C_{1}\right)$, low environmental effect $\left(C_{2}\right)$, large capacity $\left(C_{3}\right)$, improved safety $\left(C_{4}\right)$, high comfort $\left(C_{5}\right)$, high accessibility $\left(C_{6}\right)$, improved reliability $\left(C_{7}\right)$, low number of interchanged required $\left(C_{8}\right)$, and faster journey time $\left(C_{9}\right)$ by which to evaluate the seven alternatives. The hierarchical structure of these alternatives and criteria is shown in Fig. 6 below.

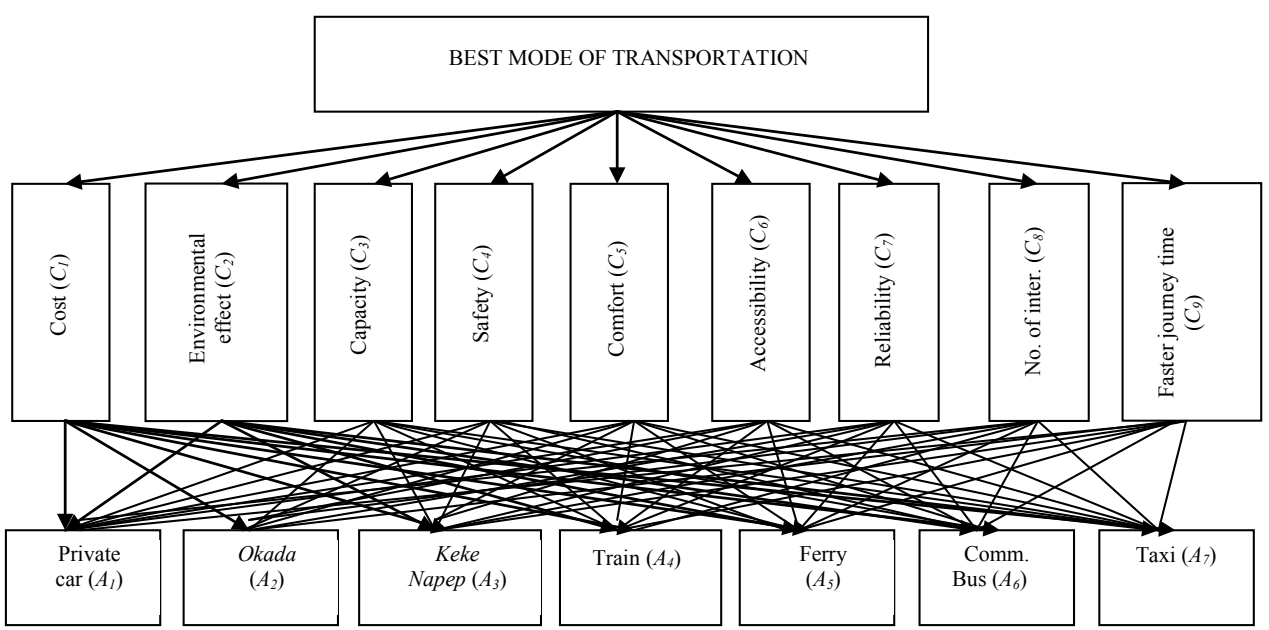

Fig. 6.

Hierarchical Structure of the Criteria and Alternatives

\subsection{Using Fuzzy Sets in Multi-Criterion Decision Making}

Let $r_{i j}$ denote the numerical value assigned to the relative significance/importance (i.e. ratios) of criteria $C_{i}$ and $C_{j}$ according to the "intensity of importance" fuzzy scale given in Table 1 . If $C_{i}$ and $C_{j}$ are equally important, then $r_{i j}=1$; if $C_{i}$ is more important than $C_{j}$, then $r_{i j}>1$; and if $C_{i}$ is less important than $C_{j}$, then $r_{i j}<1$; Table 2 has positive entries everywhere and it satisfies the reciprocal property, i.e. $r_{j i}=$ $1 / r_{i j}$. Here $r_{i j}$ are in the form of TFNs and therefore, inverse operation on TFNs is used to get their reciprocals. Normalized average weights (priorities) are computed from the matrix, as shown in Table 3. Lootsma showed that normalized column and row weights are as good enough as 
normalized eigen vectors (Lootsma, 1980). In this, the average of the two (row and column) normalized weights is used as the final weight. Alternatives (modes of transportation) are also compared in pairwise manner under each criterion.

Tables 2-4 were computed by using Eqs. (2$5)$. The row sum (RS) and CS were computed using Eq. (2) while the inverse normalization
(IN) was computed by using Eq. (4). Priority of criteria and priority of alternatives are then multiplied (fuzzy multiplication) as shown in Table 4 and added for each of the alternative mode to obtain the final scores.

The defuzzication is done using Centroid method (Opricovic and Tzeng, 2003) by using Eq. (5) to get the crisp score of the alternatives and it is shown in Table 5.

Table 2

Matrix of Relative Significance of Decision Criteria

\begin{tabular}{|c|c|c|c|c|c|}
\hline Criteria & $\mathrm{C} 1$ & $\mathrm{C} 2$ & $\mathrm{C} 3$ & $\mathrm{C} 4$ & $\mathrm{C} 5$ \\
\hline $\mathrm{C} 1$ & {$[1,1,1]$} & {$[0.25,0.33,0.5]$} & {$[4,5,6]$} & {$[0.17,0.2,0.25]$} & {$[1,1,1]$} \\
\hline $\mathrm{C} 2$ & {$[2,3,4]$} & {$[1,1,1]$} & {$[8,9,10]$} & {$[1,1,1]$} & {$[4,5,6]$} \\
\hline $\mathrm{C} 3$ & {$[0.17,0.2,0.25]$} & {$[0.1,0.11,0.13]$} & {$[1,1,1]$} & {$[0.1,0.11,0.13]$} & {$[0.17,0.2,0.25]$} \\
\hline $\mathrm{C} 4$ & {$[4,5,6]$} & {$[1,1,1]$} & {$[8,9,10]$} & {$[1,1,1]$} & {$[4,5,6]$} \\
\hline $\mathrm{C} 5$ & {$[1,1,1]$} & {$[0.17,0.2,0.25]$} & {$[4,5,6]$} & {$[0.17,0.2,0.25]$} & {$[1,1,1]$} \\
\hline C6 & {$[2,3,4]$} & {$[0.25,0.33,0.5]$} & {$[6,7,8]$} & {$[0.25,0.33,0.5]$} & {$[2,3,4]$} \\
\hline $\mathrm{C} 7$ & {$[2,3,4]$} & {$[0.25,0.33,0.5]$} & {$[6,7,8]$} & {$[0.25,0.33,0.5]$} & {$[2,3,4]$} \\
\hline $\mathrm{C} 8$ & {$[0.17,0.2,0.25]$} & {$[0.13,0.14,0.17]$} & {$[2,3,4]$} & {$[0.1,0.11,0.13]$} & {$[0.17,0.2,0.25]$} \\
\hline C9 & {$[0.25,0.33,0.5]$} & {$[0.17,0.2,0.25]$} & {$[4,5,6]$} & {$[0.13,0.14,0.17]$} & {$[0.25,0.33,0.5]$} \\
\hline CS & {$[12.59,16.73,21]$} & {$[3.32,3.64,4.3]$} & {$[43,51,59]$} & {$[3.17,3.42,3.93]$} & {$[14.59,18.73,23]$} \\
\hline Criteria & $\mathrm{C} 6$ & $\mathrm{C} 7$ & $\mathrm{C} 8$ & C9 & $\mathrm{RS}$ \\
\hline $\mathrm{C} 1$ & {$[0.25,0.33,0.5]$} & {$[0.25,0.33,0.5]$} & {$[4,5,6]$} & {$[2,3,4]$} & {$[12.92,16.19,19.75]$} \\
\hline $\mathrm{C} 2$ & {$[2,3,4]$} & {$[2,3,4]$} & {$[6,7,8]$} & {$[4,5,6]$} & {$[30,37,44]$} \\
\hline $\mathrm{C} 3$ & {$[0.13,0.14,0.17]$} & {$[0.13,0.14,0.17]$} & {$[0.25,0.33,0.5]$} & {$[0.17,0.2,0.25]$} & {$[2.22,2.43,2.85]$} \\
\hline $\mathrm{C} 4$ & {$[2,3,4]$} & {$[2,3,4]$} & {$[8,9,10]$} & {$[6,7,8]$} & {$[36,43,50]$} \\
\hline $\mathrm{C} 5$ & {$[0.25,0.33,0.5]$} & {$[0.25,0.33,0.5]$} & {$[4,5,6]$} & {$[2,3,4]$} & {$[12.84,16.06,19.5]$} \\
\hline C6 & {$[1,1,1]$} & {$[1,1,1]$} & {$[6,7,8]$} & {$[2,3,4]$} & {$[20.5,25.66,31]$} \\
\hline $\mathrm{C} 7$ & {$[1,1,1]$} & {$[1,1,1]$} & {$[6,7,8]$} & {$[2,3,4]$} & {$[20.5,25.66,31]$} \\
\hline $\mathrm{C} 8$ & {$[0.13,0.14,0.17]$} & {$[0.13,0.14,0.17]$} & {$[1,1,1]$} & {$[0.25,0.33,0.5]$} & {$[4.08,5.26,6.64]$} \\
\hline C9 & {$[0.25,0.33,0.5]$} & {$[0.25,0.33,0.5]$} & {$[2,3,4]$} & {$[1,1,1]$} & {$[8.3,10.66,13.42]$} \\
\hline CS & {$[7.01,9.27,11.84]$} & {$[7.01,9.27,11.84]$} & \multicolumn{3}{|c|}{$[37.25,44.43,51.5][19.42,25.53,31.75] 147.36,181.92,218.16$} \\
\hline & $\mathrm{RS}=$ Row Sum & \multicolumn{4}{|c|}{$\mathrm{CS}=$ Column Sum } \\
\hline
\end{tabular}

As mentioned in the previous section, fuzzy-AHP was used to determine the weight of criteria to be used. The pairwise comparisons of criteria were based on six linguistic terms on Table 1 and the corresponding triangular fuzzy numbers were decided by the decision maker. The hierarchy of the criteria is based on the outcome of the survey as shown in Fig. 3. The first step in the evaluation is preparing 
the comparison matrix of criteria using Table 1. As shown in Table 2 the criteria were compared together towards achieving the main goal (evaluation of best mode of transportation). The column sum (CS) and row sum (RS) were computed by adding the matrix on the column and row respectively as shown in Table 2. After the normalization process, the average priorities of the criteria were calculated as shown in Table 3. The average priority of criteria indicates the importance of the criteria towards the main goal. The most important criteria is Safety $\mathbf{C}_{4}$ with average priority of $[0.21,0.27,0.33]$, followed by Environmental Effect $\mathbf{C}_{2}$ with average priority of $[0.19,0.24,0.30]$, while the least important is Capacity $\mathrm{C}_{3}$ with the smallest average priority of $[0.02,0.02,0.02]$.

Table 3

Average Priority TFN's of Criteria

\begin{tabular}{|c|c|c|c|c|c|}
\hline Criteria & $\mathrm{C} 1$ & $\mathrm{C} 2$ & C3 & $\mathrm{C} 4$ & $\mathrm{C} 5$ \\
\hline RS & {$[12.92,16.19,19.75]$} & {$[30,37,44]$} & {$[2.22,2.43,2.85]$} & {$[36,43,50]$} & {$[12.84,16.06,19.5]$} \\
\hline CS & {$[12.59,16.73,21]$} & {$[3.32,3.64,4.3]$} & {$[43,51,59]$} & {$[3.17,3.42,3.93]$} & {$[14.59,18.73,23]$} \\
\hline $\mathrm{N}$ & {$[0.06,0.09,0.13]$} & {$[0.14,0.20,0.30]$} & {$[0.01,0.01,0.02]$} & {$[0.17,0.24,0.34]$} & {$[0.06,0.09,0.13]$} \\
\hline IN & {$[0.05,0.06,0.08]$} & {$[0.23,0.27,0.30]$} & {$[0.02,0.02,0.02]$} & {$[0.25,0.29,0.32]$} & {$[0.04,0.05,0.07]$} \\
\hline $\begin{array}{l}\text { Average } \\
\text { Priority of } \\
\text { Criteria }\end{array}$ & {$[0.06,0.08,0.11]$} & {$[0.19,0.24,0.30]$} & {$[0.02,0.02,0.02]$} & {$[0.21,0.27,0.33]$} & {$[0.05,0.07,0.10]$} \\
\hline Criteria & C6 & C7 & $\mathrm{C} 8$ & C9 & \\
\hline RS & {$[20.5,25.66,31]$} & {$[20.5,25.66,31]$} & {$[4.08,5.26,6.64]$} & {$[8.3,10.66,13.42]$} & \\
\hline CS & {$[7.01,9.27,11.84]$} & {$[7.01,9.27,11.84]$} & {$[37.25,44.43,51.5]$} & {$[19.42,25.53,31.75]$} & \\
\hline $\mathrm{N}^{*}$ & {$[0.09,0.14,0.21]$} & {$[0.09,0.14,0.21]$} & {$[0.02,0.03,0.05]$} & {$[0.04,0.06,0.09]$} & \\
\hline $\mathrm{IN}^{*}$ & {$[0.08,0.11,0.14]$} & {$[0.08,0.11,0.14]$} & {$[0.02,0.02,0.03]$} & {$[0.03,0.04,0.05]$} & \\
\hline $\begin{array}{l}\text { Average } \\
\text { Priority of } \\
\text { Criteria }\end{array}$ & {$[0.09,0.13,0.18]$} & {$[0.09,0.13,0.18]$} & {$[0.02,0.03,0.04]$} & {$[0.04,0.05,0.07]$} & \\
\hline & RS=Row Sum & & $\mathrm{CS}=$ Column Sum & & \\
\hline
\end{tabular}

${ }^{*} N=$ Normalization, $I N=$ Inverse Normalization

After computing the average priorities of the criteria, the alternatives' matrix is developed based on the degree of each alternative towards achieving the criteria. For instance, under the safety criterion, the safest mode of transportation will have the highest weight while the least safe will have the lowest weight. The average priority of criteria (APC) is multiplied by the individual average priority of alternatives to get the average priority score of each alternative as shown in Table 4. 


\section{Table 4}

Computation of Final Scores of Alternatives

\begin{tabular}{|c|c|c|c|c|c|}
\hline \multirow{4}{*}{$\begin{array}{l}\text { Criteria } \\
\text { A.P.C }\end{array}$} & \multirow{4}{*}{$\begin{array}{l}\mathrm{A}_{1} \\
\mathrm{~A}_{2}\end{array}$} & \multirow{3}{*}{$\begin{array}{c}\mathrm{C}_{1} \\
{[0.06,0.08,0.11]} \\
{[0.04,0.06,0.09]}\end{array}$} & \multirow{3}{*}{$\begin{array}{c}\mathrm{C}_{2} \\
{[0.19,0.24,0.30]} \\
{[0.10,0.14,0.20]}\end{array}$} & \multirow{3}{*}{$\begin{array}{c}\mathrm{C}_{3} \\
{[0.02,0.02,0.02]} \\
{[0.05,0.07,0.11]}\end{array}$} & \multirow{3}{*}{$\begin{array}{c}\mathrm{C}_{4} \\
{[0.21,0.27,0.33]} \\
{[0.11,0.16,0.25]}\end{array}$} \\
\hline & & & & & \\
\hline & & & & & \\
\hline & & {$[0.03,0.04,0.05]$} & {$[0.27,0.36,0.47]$} & {$[0.03,0.03,0.04]$} & {$[0.03,0.04,0.05]$} \\
\hline Average & $\mathrm{A}_{3}$ & {$[0.07,0.10,0.15]$} & {$[0.16,0.22,0.31]$} & {$[0.03,0.05,0.06]$} & {$[0.05,0.08,0.12]$} \\
\hline Priority & $\mathrm{A}_{4}$ & {$[0.27,0.37,0.48]$} & {$[0.03,0.03,0.04]$} & {$[0.29,0.38,0.48]$} & {$[0.25,0.35,0.47]$} \\
\hline Of & $\mathrm{A}_{5}$ & {$[0.15,0.22,0.32]$} & {$[0.03,0.05,0.07]$} & {$[0.17,0.23,0.33]$} & {$[0.14,0.21,0.31]$} \\
\hline \multirow[t]{2}{*}{ Alternatives } & $\mathrm{A}_{6}$ & {$[0.10,0.15,0.23]$} & {$[0.05,0.07,0.10]$} & {$[0.11,0.16,0.23]$} & {$[0.04,0.05,0.08]$} \\
\hline & $\mathrm{A}_{7}$ & {$[0.05,0.08,0.11]$} & {$[0.09,0.13,0.18]$} & {$[0.05,0.07,0.11]$} & {$[0.07,0.11,0.17]$} \\
\hline & $\mathrm{A}_{1}$ & {$[0.0024,0.0048,0.0099]$} & {$[0.019,0.0336,0.06]$} & {$[0.001,0.0014,0.0022]$} & {$[0.0231,0.0432,0.0825]$} \\
\hline & $\mathrm{A}_{2}$ & {$[0.0018,0.0032,0.0055]$} & {$[0.0513,0.0864,0.141]$} & {$[0.0006,0.0006,0.0008]$} & {$[0.0063,0.0108,0.0165]$} \\
\hline Average & $\mathrm{A}_{3}$ & {$[0.0042,0.008,0.0165]$} & {$[0.0304,0.0528,0.093]$} & {$[0.0006,0.001,0.0012]$} & {$[0.0105,0.0216,0.0396]$} \\
\hline Priority & $\mathrm{A}_{4}$ & {$[0.0162,0.0296,0.0528]$} & {$[0.0057,0.0072,0.012]$} & {$[0.0058,0.0076,0.0096]$} & {$[0.0525,0.00945,0.155]$} \\
\hline Of & $\mathrm{A}_{5}$ & {$[0.009,0.0176,0.0352]$} & {$[0.0057,0.012,0.021]$} & {$[0.0034,0.0046,0.0066]$} & {$[0.0294,0.0567,0.1023]$} \\
\hline \multirow[t]{2}{*}{ Scores } & $\mathrm{A}_{6}$ & {$[0.006,0.012,0.0253]$} & {$[0.0095,0.0168,0.03]$} & {$[0.0022,0.0032,0.0046]$} & {$[0.0084,0.0135,0.0264]$} \\
\hline & $\mathrm{A}_{7}$ & {$[0.003,0.0064,0.0121]$} & {$[0.0171,0.0312,0.054]$} & {$[0.001,0.0014,0.0022]$} & {$[0.0147,0.0297,0.0561$} \\
\hline \multicolumn{2}{|l|}{$\mathrm{C}_{5}$} & $\mathrm{C}_{6}$ & $\mathrm{C}_{7}$ & $\mathrm{C}_{8}$ & $\mathrm{C}_{9}$ \\
\hline \multicolumn{2}{|c|}{$[0.30,0.39,0.50]$} & {$[0.25,0.34,0.43]$} & {$[0.23,0.30,0.38]$} & {$[0.20,0.24,0.30]$} & {$[0.13,0.18,0.26]$} \\
\hline \multicolumn{2}{|c|}{$[0.03,0.03,0.04]$} & {$[0.14,0.17,0.22]$} & {$[0.04,0.05,0.07]$} & {$[0.20,0.24,0.30]$} & {$[0.28,0.38,0.50]$} \\
\hline \multicolumn{2}{|c|}{$[0.04,0.05,0.08]$} & {$[0.07,0.09,0.13]$} & {$[0.04,0.05,0.07]$} & {$[0.08,0.11,0.17]$} & {$[0.06,0.08,0.11]$} \\
\hline \multicolumn{2}{|c|}{$[0.07,0.10,0.15]$} & {$[0.03,0.03,0.03]$} & {$[0.23,0.30,0.38]$} & {$[0.02,0.03,0.03]$} & {$[0.03,0.04,0.05]$} \\
\hline \multicolumn{2}{|c|}{$[0.09,0.14,0.21]$} & {$[0.03,0.03,0.03]$} & {$[0.09,0.13,0.19]$} & {$[0.03,0.05,0.07]$} & {$[0.06,0.08,0.11$} \\
\hline \multicolumn{2}{|c|}{$[0.05,0.07,0.10]$} & {$[0.14,0.17,0.22]$} & {$[0.04,0.05,0.07]$} & {$[0.06,0.08,0.11]$} & {$[0.06,0.08,0.11]$} \\
\hline \multicolumn{2}{|c|}{$[0.15,0.22,0.31]$} & {$[0.14,0.17,0.22]$} & {$[0.09,0.13,0.19]$} & {$[0.20,0.24,0.30]$} & {$[0.13,0.18,0.26]$} \\
\hline \multicolumn{6}{|c|}{$[0.015,0.0273,0.05][0.0225,0.0442,0.0774][0.0207,0.039,0.0684][0.004,0.0072,0.012][0.0052,0.009,0.0182]$} \\
\hline \multicolumn{2}{|c|}{$[0.0015,0.002,0.004]$} & {$[0.0126,0.0221,0.0396]$} & {$[0.0036,0.0065,0.0126]$} & {$[0.004,0.0072,0.012]$} & {$[0.0112,0.019,0.035]$} \\
\hline \multicolumn{2}{|c|}{$[0.002,0.0035,0.008]$} & {$[0.0063,0.0117,0.0234]$} & {$[0.0036,0.0065,0.0126]$} & {$[0.0016,0.0033,0.0068]$} & {$[0.0024,0.004,0.0077]$} \\
\hline \multicolumn{2}{|c|}{$[0.0035,0.007,0.015]$} & {$[0.0027,0.0039,0.0054]$} & {$[0.0207,0.039,0.0684]$} & {$[0.0004,0.0009,0.0012]$} & {$[0.0012,0.002,0.0035]$} \\
\hline \multicolumn{2}{|c|}{$[0.0045,0.0098,0.02]$} & {$[0.0027,0.0039,0.0054]$} & {$[0.0081,0.0169,0.0342]$} & {$[0.0006,0.0009,0.0012]$} & {$[0.0024,0.004,0.0077]$} \\
\hline \multicolumn{2}{|c|}{$[0.0025,0.0049,0.01]$} & {$[0.0126,0.0221,0.0396]$} & {$[0.0036,0.0065,0.0126]$} & {$[0.0012,0.0024,0.0044]$} & {$[0.0024,0.004,0.0077]$} \\
\hline \multicolumn{2}{|c|}{$[0.0075,0.015,0.03]$} & {$[0.0126,0.0221,0.0396]$} & {$[0.0081,0.0169,0.0342]$} & {$[0.004,0.0072,0.012]$} & {$[0.0052,0.009,0.0182]$} \\
\hline
\end{tabular}

After the average priority score is computed, the average priority scores of each alternative is then summed up on the row, to get the final ranking/score of the alternatives. For $\mathrm{A}_{1},[0.0024,0.0048,0.0099]$, [0.019,0.0336,0.06], [0.001,0.0014,0.0022], $[0.0231,0.0432,0.0825],[0.015,0.0273,0.05],[0.0225,0.0442,0.0774],[0.0207,0.039,0.0684]$, $[0.004,0.0072,0.012]$, and $[0.0052,0.009,0.0182]$ were summed up to get the final ranking of $A_{1}$ has $[0.1129,0.2097,0.3806]$. This was done for all the alternatives and their final ranking are as follows: 
$\mathrm{A}_{2}=[0.0929,0.1579,0.267]$,

$\mathrm{A}_{3}=[0.0616,0.1124,0.2088]$,

$\mathrm{A}_{4}=[0.1087,0.10665,0.323]$,

$\mathrm{A}_{5}=[0.0658,0.1264,0.2346]$,

$\mathrm{A}_{6}=[0.0484,0.0854,0.1606]$,

$A_{7}=[0.0732,0.1393,0.2594]$.
After the evaluation process, the selection process was carried out by converting the fuzzy matrix in crisp score; this is called defuzzification using Eq. (5) as shown in Table 5 and Fig. 7. The alternative with the highest crisp score was selected as best mode of transportation for this case study.

Table 5

Final Ranking of Alternatives and Crisp Scores

\begin{tabular}{|c|c|c|}
\hline Alternatives & Final Ranking of Mode of Transportation & Crisp Scores \\
\hline A1 & {$[0.1129,0.2097,0.3806]$} & 0.2344 \\
\hline A2 & {$[0.0929,0.1579,0.267]$} & 0.1726 \\
\hline A3 & {$[0.0616,0.1124,0.2088]$} & 0.1276 \\
\hline A4 & {$[0.1087,0.10665,0.323]$} & 0.1795 \\
\hline A5 & {$[0.0658,0.1264,0.2346]$} & 0.1423 \\
\hline A6 & {$[0.0484,0.0854,0.1606]$} & 0.0981 \\
\hline A7 & {$[0.0732,0.1393,0.2594]$} & 0.1573 \\
\hline
\end{tabular}

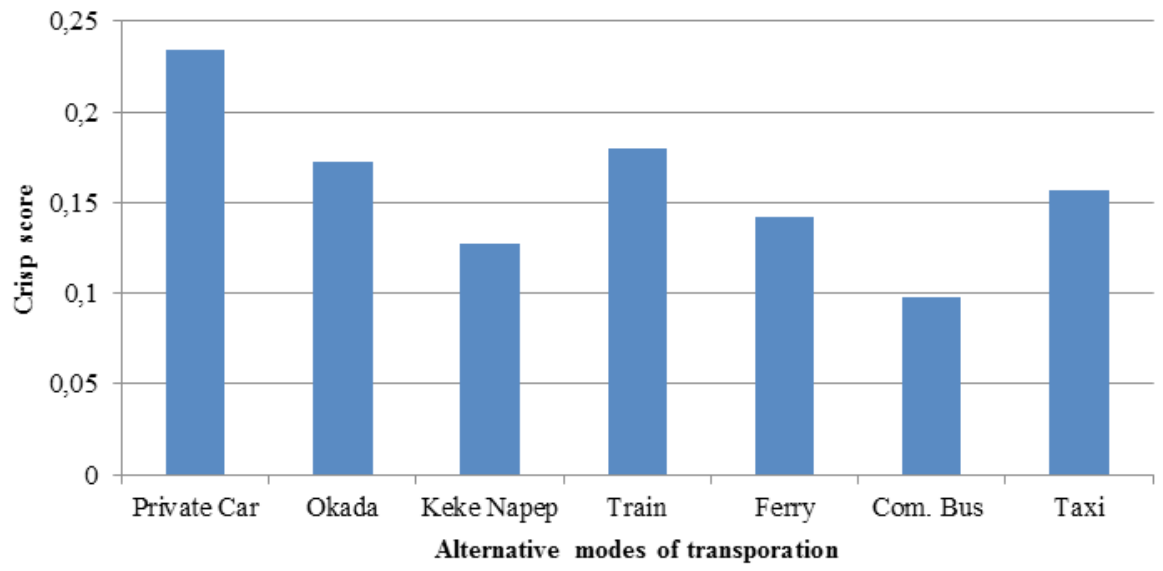

Fig. 7.

Priority of Alternatives after Defuzzification

\section{Conclusion}

In this paper, the selection of transportation mode in Lagos metropolis is illustrated by incorporating fuzzy sets in Saaty's priority theory. As "importance" is normally expressed in subjective/linguistic terms, "intensity of importance" scale is fuzzified and expressed in the form of TFN. Seven alternatives (mode of transportation) and nine decision criteria were determined and then priority theory is used. Priority theory estimates the weights (priorities) of decision criteria using pair-wise comparison method. Alternatives were also compared in pairwise manner under each criterion. Adjusted 
average score of the normalized row and the column sum is suggested to confirm the priorities. The final scores of each of the modes (alternatives) were evaluated by multiplying (fuzzy arithmetic) the priorities and then adding them.

Based on this result as shown in Table 5, private cars $A_{1}$ is selected best mode of transportation, followed by train $A_{4}$, okada $A_{2}, \operatorname{taxi} A_{7}$ and so on as shown in Fig. 7.

\section{Recommendation}

This research is based on the performance evaluation of mode of transportation in Lagos and there is room for improvement for the operators of the modes of transportation that have low ranking. All they need to do is to check the criteria in which they have low weight and try to improve on such criteria. For example, the commercial bus has a high fuzzy weight under accessibility $\left(C_{6}\right)$ but scored very low on reliability $\left(C_{7}\right)$ and environmental effect $\left(A_{2}\right)$. Therefore, operators of this mode of transportation should try to find a way to improve their ranking on improved reliability and low environmental effect.

\section{References}

Arslan, T.; Khisty, C.J. 2005. A rational reasoning method from perceptions in route choice, Fuzzy Sets and Systems. DOI: http://dx.doi.org/10.1016/j. fss.2004.03.021, 150(3): 419-435.

Buckley, J.J. 1985. Fuzzy hierarchy analysis, Fuzzy Sets and Systems. DOI: http://dx.doi.org/10.1016/01650114(85)90090-9, 17(3): 233-247.

Chang, D.Y. 1996. Applications of the extent analysis method on fuzzy AHP, European Journal of Operational Research. DOI: http://dx.doi.org/10.1016/03772217(95)00300-2, 95(3): 649-655.
Climaco, J. 1997. Multicriteria Analysis. New York: Springer-Verlag.

Dubois, D.; Prade, H. 1980. Fuzzy sets and systems: theory and applications, Academic Press, New York.

Huang, C.C.; Chu, P.Y; Chiang, Y.H. 2008. A fuzzy AHP application in government-sponsored $\mathrm{R} \& \mathrm{D}$ project selection, Omega. DOI: http://dx.doi.org/10.1016/j. omega.2006.05.003, 36(6): 1038-1052.

Kahraman, C.; Cebeci, U.; Ulukan, Z. 2003. Multi-criteria supplier selection using fuzzy AHP, Logistics Information Management. DOI: http://dx.doi. org/10.1108/09576050310503367, 16(6): 382-394.

Lootsma, F.A. 1980. Saaty's priority theory and the nomination of a senior professor in operations research, European Journal of Operational Research. DOI: http:// dx.doi.org/10.1016/0377-2217(80)90189-7, 14(6): 380-388.

Mechefske, C.K.; Wang, Z. 2001. Using fuzzy linguistics to select optimum maintenance and condition monitoring strategies, Mechanical Systems and Signal Processing. DOI: http://dx.doi.org/10.1006/ mssp.2000.1395, 15(6): 1129-1140.

Odeyale, S.O.; Alamu, O.J.; Odeyale, E.O. 2013. The Analytical Hierarchy Process Concept for Maintenance Strategy Selection in Manufacturing Industries, Pacific Journal of Science and Technology, 14(1): 223-233.

Opricovic, S.; Tzeng, G.H. 2003. Defuzzification within a multi-criteria decision model, International Journal of Uncertainty, Fuzziness and Knowledge-Based Systems. DOI: http://dx.doi.org/10.1142/S0218488503002387, 11(5): 635-652.

Pan, N.F. 2008. Fuzzy AHP approach for selecting the suitable bridge construction method, Automation in Construction. DOI: http://dx.doi.org/10.1016/j. autcon.2008.03.005, 17(8): 958-965. 
Pohekar, S.D.; Ramachandran, M. 2004. Application of multi-criteria decision making to sustainable energy planning - A review, Renewable and Sustainable Energy Reviews. DOI: http://dx.doi.org/10.1016/j. rser.2003.12.007, 8(4): 365-381.

Saaty, T.L.; Vargas, L.G. 1982. The logic of priorities applications in business, Energy, Health and Transportation, U.S.A.: Kluwer-Nijhoff Publishing.

Tuzkaya, U.R. 2009. Evaluating the environmental effects of transportation modes using an integrated methodology and an application, International Journal of Environmental Science \& Technology. DOI: http://dx.doi. org/10.1007/BF03327632, 6(2): 277-290.

Tuzkaya, U.R.; Önüt, S. 2008. A fuzzy analytic network process based approach to transportation-mode selection between Turkey and Germany: A case study, Information Sciences. DOI: http://dx.doi.org/10.1016/j. ins.2008.03.015, 178(15): 3132-3145.

Van Laarhoven, P.J.M.; Pedrycz, W. 1983. A fuzzy extension of Saaty'spriority theory, Fuzzy Sets and Systems. DOI: http://dx.doi.org/10.1016/S0165-0114(83)800827, 11(1-3): 199-227.

Verma, A.K.; 2006. Selecting optimal maintenance strategy using priority theory. In Proceedings of the International Conference on Quality and Reliability in Aerospace Systems, Hyderabad, India, 2: 285-296.

Wang, J.J.; Yang, D.L. 2007. Using a hybrid multicriteria decision aid method for information systems outsourcing, Computers \& Operations Research. DOI: http://dx.doi.org/10.1016/j.cor.2006.01.017, 34(12): 3691-3700.

Wang, Y.M.; Chin, K.S. 2008. A linear goal programming priority method for fuzzy analytic hierarchy process and its applications in new product screening, International Journal of Approximate Reasoning. DOI: http://dx.doi. org/10.1016/j.ijar.2008.04.004, 49(2): 451-465.
Yager, R.R. 1978. Fuzzy decision making including unequal objectives, Fuzzy Sets and Systems. DOI: http:// dx.doi.org/10.1016/0165-0114(78)90010-6, 1(2): 87-95.

Zimmermann, H.J. 1987. Fuzzy sets, decision making and expert systems, Kluwer Academic Publishers, Norwell, MA.

Zimmermann, H.J. 1985. Fuzzy set theory and its applications, Hingham, MA: Kluwer- Nijhoff Publishing. 